\title{
Renal Dendritic Cells: An Update
}

\author{
Peter Velázquez ${ }^{a} \quad$ Michael L. Dustin ${ }^{a}$ Peter J. Nelson ${ }^{b}$

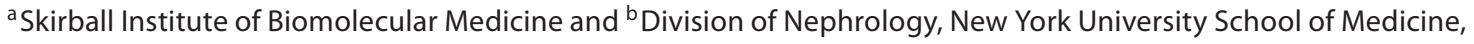 \\ New York, N.Y., USA
}

\section{Key Words}

Renal dendritic cells • Renal parencyhma • Immunology

\begin{abstract}
Discovery into the role of renal dendritic cells (rDCs) in health and disease of the kidney is rapidly accelerating. Progress in deciphering DC precursors and the heterogeneity of monocyte subsets in mice and humans is providing insight into the biology of rDCs. Recent findings have extended knowledge of the origins, anatomy and function of the rDC network at steady state and during periods of injury to the renal parenchyma. This brief review highlights these new findings and provides an update on the study of rDCs.
\end{abstract}

Copyright $\odot 2009$ S. Karger AG, Basel

\section{Steady-State Anatomic and Functional Relationships}

Renal dendritic cells (rDCs) are major constituents of the mononuclear phagocytic system (MPS) within normal kidneys $[1,2]$, but the formation and maintenance of the $\mathrm{rDC}$ network is not yet fully understood. rDCs derive from a common bone marrow macrophage and DC precursor, which also gives rise to circulating and patrolling $\mathrm{Csflr}^{+} \mathrm{Grl}^{+}$and $\mathrm{Csflr}^{+} \mathrm{Grl}^{-}$blood monocytes [3, 4]. Although yet poorly understood for the kidney, studies in other nonlymphoid and lymphoid organs suggest that $\mathrm{Csflr}^{+} \mathrm{Grl}^{-}$or $\mathrm{Csflr}^{+} \mathrm{Grl}^{+}$blood monocytes or perhaps nonmonocyte 'pre-DCs' may serve as precursors for $\mathrm{rDC}$ during cellular turnover within the renal MPS [3-6]. Recent characterizations of the renal MPS suggest that rDCs, phenotyped as $\mathrm{Grl}^{-}$, may derive from 'noninflammatory' Csf1 $\mathrm{r}^{+} \mathrm{Grl}^{-}$blood monocytes [7, 8]; however, speculation remains that $\mathrm{rDCs}$ at steady state might also convert or mature from 'inflammatory' $\mathrm{Csf} 1 \mathrm{r}^{+} \mathrm{Grl}^{+}$blood monocytes, particularly following resolution of renal inflammation [4]. Intriguingly, studies utilizing Csf1rEGFP mice have shown that the renal MPS begins to form in the renal interstitium prior to nephrogenesis [9], raising the possibility that vestigial niches of intrarenal 'preDCs' might reside within the mature kidney as well. Further research is needed to determine the contribution of these potential intrarenal and circulating sources towards maintenance of the rDC network at steady state.

Wherever the precursors for the mature rDC network reside anatomically, the major ligand for Csf1r, macrophage colony-stimulating factor, and for Flt3, Flt3 ligand (Flt3L), are emerging as two of its central poietins. Several groups have now demonstrated that granulocyte macrophage colony-stimulating factor-derived DCs, whether propagated from bone marrow cultures ex vivo or detected in vivo, represent inflammatory DCs, not DCs at steady state as originally conceived [3]. Flt3L-derived DCs are phenotypically similar to DCs at steady state [3], however, and recent studies in nonhuman primates recapitulate murine studies which showed transient increases in all $\mathrm{rDC}$ subsets with administration of Flt3L [10]. Similar to the requirement for ligation of Flt3 for homeostatic DC development in peripheral lymphoid tissues [11], disruption of the Flt3-Flt3L interaction in

\section{KARGER}

() 2009 S. Karger AG, Basel

Fax +41613061234 E-Mail karger@karger.ch www.karger.com
Accessible online at: www.karger.com/nee
Peter J. Nelson, MD

Division of Nephrology, New York University School of Medicine

Smilow Research Center, 522 First Avenue

New York, NY 10016 (USA)

Tel. +1 212263 7681, Fax +1 212263 7683, E-Mail peter.nelson2@nyumc.org 
Fig. 1. Trophic interactions between rDCs and renal epithelial cells cocultured in 3-dimensional collagen matrices. a The fecundity of rDCs ex vivo is captured by measuring over a 5 -day period the morphologic area of spreading and number of $\mathrm{GFP}^{+} \mathrm{rDCs}$ isolated from $\mathrm{CX}_{3} \mathrm{CR} 1^{\mathrm{GFP} /+}$ mice by confocal microscopy. rDCs cultured alone $(\bigcirc)$ do not spread, whereas rDCs cocultured with mouse IMCD-3 renal epithelial cells $(\mathbf{)})$ survive, proliferate and spread, suggesting trophic, paracrine interactions between $\mathrm{rDCs}$ and renal epithelial cells. b Images captured by confocal microscopy at day 5 showing the following: $\mathrm{GFP}^{+} \mathrm{rDCs}$ cultured alone [left panel: small green cells (white in the printed version) in the low-power tile scan $(2.2 \times 2.2 \mathrm{~mm})$ ]; mouse IMCD-3 cells cocultured with $\mathrm{GFP}^{+} \mathrm{rDCs}$ (middle panel: larger, stellate-shaped green cells (white in the printed version) in the low-power tile scan $(2.2$ $\times 2.2 \mathrm{~mm}$ )] , and a high-power view of branching mouse IMCD3 tubules (right panel; arrows show the upper border of a tubule; high-power $\times 63$ objective) intimately associated in coculture with $\mathrm{GFP}^{+}$rDCs. Unlike rDCs cultured alone (left panel), rDCs cocultured with renal epithelial cells survive, proliferate and morphologically differentiate (middle panel).

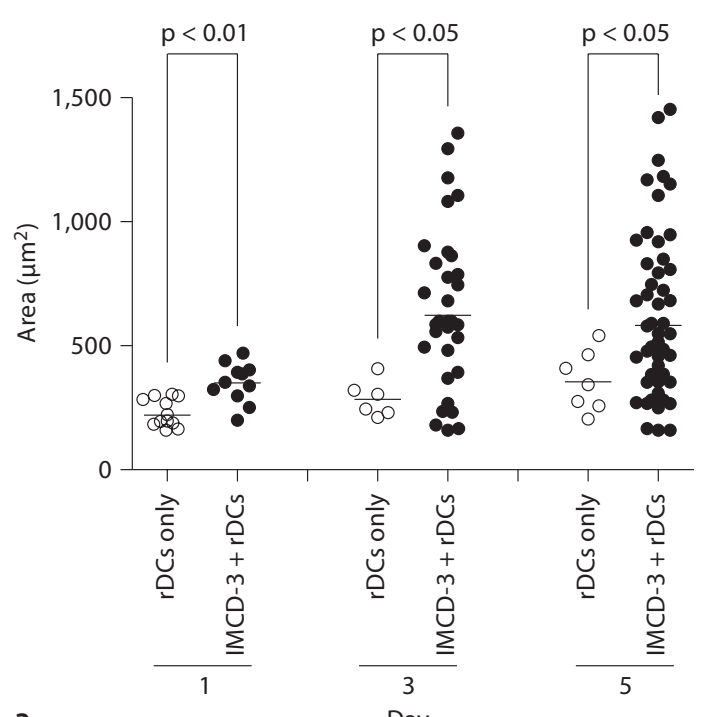

a

Day b

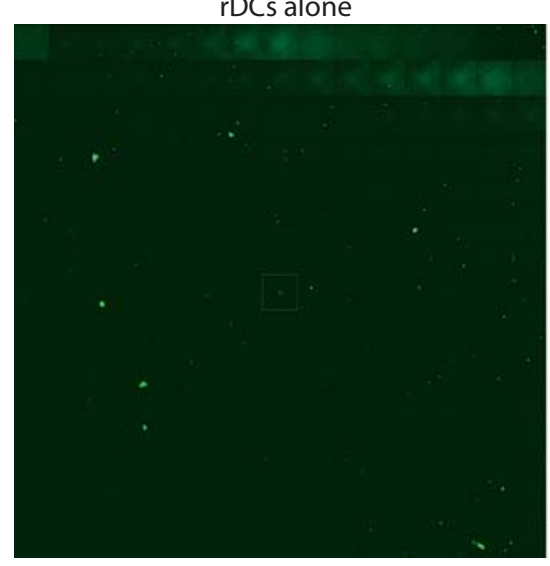

rDCs + IMCD-3

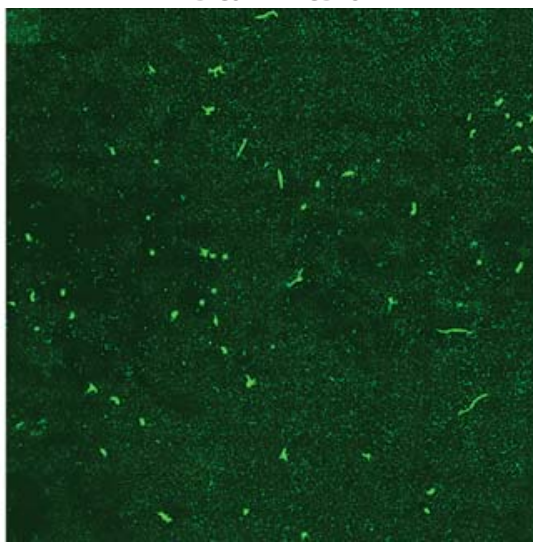

$\mathrm{rDCs}+\mathrm{IMCD}-3$

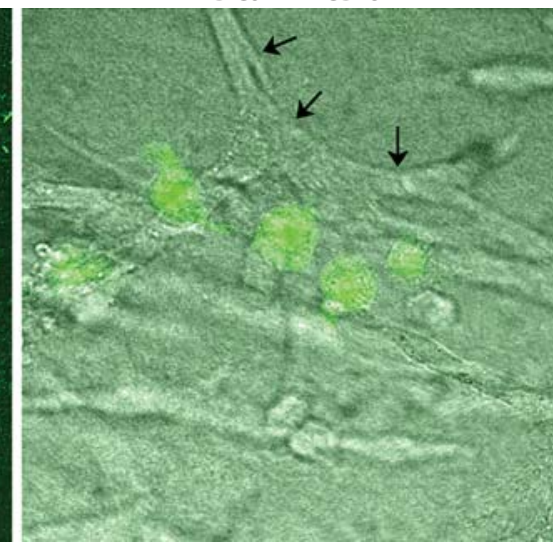

vivo may cause a severe deficiency in rDCs [A. Thomson, pers. commun.]. While it is yet unclear whether Flt3L is produced by the renal parenchyma as a trophic factor for rDCs, macrophage colony-stimulating factor is known to be expressed by renal epithelial cells [1] and to maintain conventional and plasmacytoid DCs [12]. In support of this, we have found that tissue-resident mouse rDCs isolated from normal kidneys of adult $\mathrm{CX}_{3} \mathrm{CR} 1^{\mathrm{GFP} /+}$ mice survive and proliferate rather than die when cocultured with mouse renal epithelial cells ex vivo (fig. 1). This con- served ability to proliferate ex vivo suggests that at least a subset of $\mathrm{rDC}$ is not terminally differentiated in vivo.

Experimental evidence is mounting that $\mathrm{rDCs}$ help to maintain peripheral tolerance in the kidney at steady state [1]. Exogenous, nonself antigen introduced into normal kidneys is captured by rDCs and presented in draining renal lymph nodes, leading to immune activation and proliferation of antigen-specific $\mathrm{CD}^{+}{ }^{+} \mathrm{T}$ lymphocytes [13]. Notwithstanding, normal kidneys must also continually process glomerular ultrafiltrates of blood along the 
course of nephrons that may contain otherwise harmless endogenous antigens without loss of tolerance to these potential urinary antigens. This was discovered to occur in part through $\mathrm{rDC}$-independent cross-tolerance of $\mathrm{CD}^{+}$lymphocytes to these soluble filtrated antigens after bulk transport of the antigens to renal lymph nodes [14]. Any additional role of major histocompatibility complex transfer between rDCs and extrarenal DCs [15] in generating this renal immunity to exogenous antigens versus renal tolerance to endogenous antigens is unclear.

\section{rDCs in Renal Inflammation}

Using specific markers to localize rDCs in human biopsy specimens, several new studies have demonstrated renal compartment-specific accumulation of $\mathrm{rDC}$ subsets during renal inflammation; however, the pathogenic role of this unique $\mathrm{rDC}$ traffic is poorly understood. $\mathrm{BDCA}^{+}$conventional and $\mathrm{BDCA}^{+}$plasmacytoid $\mathrm{rDCs}$ accumulate in the renal interstitium [16], whereas $\mathrm{BDCA}^{+}$plasmacytoid rDCs preferentially accumulate in glomeruli [17], in patients with active lupus nephritis. Likewise, $\mathrm{DC}^{-S I G N}{ }^{+}$conventional $\mathrm{rDCs}$ are not readily detected in diseased glomeruli in other nonproliferative and proliferative glomerular diseases, whereas they occur in abundance, along with $\mathrm{BDCA} 2^{+}$plasmacytoid rDCs, in the renal interstitium [18]. In some cases, tertiary lymphoid aggregates composed of $\mathrm{CD} 21^{+}$follicular rDCs and $\mathrm{CD} 20^{+} \mathrm{B}$ lymphocytes have been detected in the renal interstitium $[19,20]$. Of note, these aggregates have been observed in other nonrenal inflammatory diseases, suggesting a conserved immunologic program executed by DCs, whether resident or recruited [20]. Interestingly, paracrine communications at previously unrecognized renal neuron-rDC interfaces may be an important factor in rDC-mediated inflammation [21].

While these reports posit a positive correlation suggesting causality between the extent of inflammatory rDC accumulation and renal parenchymal injury, preliminary studies in animal models suggest a more complex role. After sequentially ablating accumulating inflammatory $\mathrm{CD}_{11 \mathrm{c}^{+}} \mathrm{rDCs}$ and all other intrarenal and extrarenal CD11c ${ }^{+} \mathrm{DC}$ subsets in mice with experimental nephrotoxic nephritis, tubulointerstitial and glomerular injury was observed to be aggravated, not ameliorated [22]. This may be due to a need for inflammatory CD11c ${ }^{+}$ rDCs to induce intrarenal CD $4^{+} \mathrm{T}$ lymphocytes to produce IL-10 that may attenuate other proinflammatory cy- tokines $[22,23]$; however, given the simultaneous ablation of all other intrarenal and extrarenal CD11c ${ }^{+}$DC subsets in these studies, several other compensatory immunocytoprotective mechanisms may have been disrupted $[24,25]$. In contrast with these potential anti-inflammatory mechanisms is the recent finding that $\mathrm{rDCs}$ facilitate the recruitment of detrimental $\mathrm{CD} 4^{+} \mathrm{T}$ lymphocytes secreting IL-17 following experimental acute urinary obstruction [26]. One possibility that may explain this dichotomy is the dual role of TGF- $\beta$, which can be produced by DCs and drives the development of regulatory $\mathrm{T}$ lymphocytes or Th17 effector T lymphocytes depending on additional cues [27]. Further research is needed to determine the dynamic pathogenic roles of steadystate and inflammatory rDCs during injury to the renal parenchyma, inquiries that will be aided by the development of specific $\mathrm{rDC}$ subset ablation systems limited to the kidney [24, 25].

\section{rDC Surveillance in Acute Kidney Injury}

Experimental acute kidney injury models are providing insights into the complexity of immunologic surveillance by rDCs [1]. Recent reports suggest that endogenously expressed ligands for Toll-like receptors contribute to activation of rDCs during renal ischemiareperfusion injury [28]. In contrast, local and systemic inflammation during lipopolysaccharide-induced acute kidney injury may not be sufficient to activate rDCs [29]. Likewise, the acute hypoxia of renal ischemia-reperfusion injury is a presumed stimulus favoring maturation of rDCs via hypoxia-inducible factor-1 $\alpha$ activation [30], but the contribution of hypoxia as compared to that from other stimuli towards further pro- versus anti-inflammatory activation of rDCs is unclear [31]. For example, hypoxic preconditioning before renal ischemia-reperfusion can also be cytoprotective, marked by the induction of heme oxygenase-1, which may contribute to suppressed maturation of rDCs [32] and their functional role via regulatory $\mathrm{T}$ lymphocytes [33]. These paradoxical findings are also exemplified by the recent speculation that TammHorsfall protein, an endogenous renal ligand for Toll-like receptor- 4 , is protective in renal ischemia-reperfusion injury via rDCs [34]. Together, these studies indicate that much remains to be learned about the integration and timing of various environmental cues in the sentinel priming of tissue-resident rDCs towards immunity and tolerance [35]. 


\section{Conclusion}

Recent research supports the paradigm that rDCs function at the nexus of innate and adaptive immunity, self-tolerance and tissue homeostasis within the kidney. It is clear that studying the communication between rDCs and other renal parenchymal cell types promises to yield insights into the maintenance and immune modulation of rDCs by homeostatic and environmental cues. While advances have been made in characterizing subsets of tissue-resident and infiltrating $\mathrm{rDC}$ at steady state and during renal injury, further research is needed to determine the surveillance and effector function of these subsets, both within the kidney and after their egress to secondary lymphoid organs. Together, these future inquiries should uncover strategies towards modulating rDCs for therapeutic benefit in various kidney diseases.

\section{Acknowledgments}

We thank Angus Thomson for helpful discussions on the development of rDCs and Lloyd Cantley for helpful discussions on IMCD-3 cells. This work was supported by the National Institutes of Health grants DK078153 (P.V.), AI055037 (M.L.D.), DK065498 (P.J.N.) and DK079498 (P.J.N.).

\section{References}

1 John R, Nelson PJ: Dendritic cells in the kidney. J Am Soc Nephrol 2007;18:2628-2635.

$\checkmark 2$ Kaissling B, Le Hir M: The renal cortical interstitium: morphological and functional aspects. Histochem Cell Biol 2008;130:247262.

3 Naik SH: Demystifying the development of dendritic cell subtypes, a little. Immunol Cell Biol 2008;86:439-452

4 Geissmann F, Auffray C, Palframan R, Wirrig C, Ciocca A, Campisi L, Narni-Mancinelli E, Lauvau G: Blood monocytes: distinct subsets, how they relate to dendritic cells, and their possible roles in the regulation of T-cell responses. Immunol Cell Biol 2008;86: 398-408.

5 Varol C, Landsman L, Fogg DK, Greenshtein L, Gildor B, Margalit R, Kalchenko V, Geissmann F, Jung S: Monocytes give rise to mucosal, but not splenic, conventional dendritic cells. J Exp Med 2007;204:171-180.

-6 Landsman L, Varol C, Jung S: Distinct differentiation potential of blood monocyte subsets in the lung. J Immunol 2007;178: 2000-2007.

-7 Soos TJ, Sims TN, Barisoni L, Lin K, Littman DR, Dustin ML, Nelson PJ: CX3CR1+ interstitial dendritic cells form a contiguous network throughout the entire kidney. Kidney Int 2006;70:591-596.

$>8$ Li L, Huang L, Sung SS, Vergis AL, Rosin DL, Rose CE Jr, Lobo PI, Okusa MD: The chemokine receptors CCR2 and CX3CR1 mediate monocyte/macrophage trafficking in kidney ischemia-reperfusion injury. Kidney Int 2008;74:1526-1537.

$\checkmark 9$ Rae F, Woods K, Sasmono T, Campanale N, Taylor D, Ovchinnikov DA, Grimmond SM, Hume DA, Ricardo SD, Little MH: Characterisation and trophic functions of murine embryonic macrophages based upon the use of a Csf1r-EGFP transgene reporter. Dev Biol 2007;308:232-246.
10 Morelli AE, Coates PT, Shufesky WJ, Barratt-Boyes SM, Fung JJ, Demetris AJ, Thomson AW: Growth factor-induced mobilization of dendritic cells in kidney and liver of rhesus macaques: implications for transplantation. Transplantation 2007;83:656662.

11 Waskow C, Liu K, Darrasse-Jeze G, Guermonprez P, Ginhoux F, Merad M, Shengelia T, Yao K, Nussenzweig M: The receptor tyrosine kinase Flt 3 is required for dendritic cell development in peripheral lymphoid tissues. Nat Immunol 2008;9:676-683.

12 Fancke B, Suter M, Hochrein H, O’Keeffe M: M-CSF: a novel plasmacytoid and conventional dendritic cell poietin. Blood 2008;111: 150-159.

13 Edgtton KL, Kausman JY, Li M, O’Sullivan K, Lo C, Hutchinson P, Yagita H, Holdsworth SR, Kitching AR: Intrarenal antigens activate CD4+ cells via co-stimulatory signals from dendritic cells. J Am Soc Nephrol 2008; 19:515-526.

14 Lukacs-Kornek V, Burgdorf S, Diehl L, Specht S, Kornek M, Kurts C: The kidneyrenal lymph node-system contributes to cross-tolerance against innocuous circulating antigen. J Immunol 2008;180:706-715.

-15 Brown K, Sacks SH, Wong W: Extensive and bidirectional transfer of major histocompatibility complex class II molecules between donor and recipient cells in vivo following solid organ transplantation. FASEB J 2008; 22:3776-3784

16 Fiore N, Castellano G, Blasi A, Capobianco C, Loverre A, Montinaro V, Netti S, Torres D, Manno C, Grandaliano G, Ranieri E, Schena FP, Gesualdo L: Immature myeloid and plasmacytoid dendritic cells infiltrate renal tubulointerstitium in patients with lupus nephritis. Mol Immunol 2008;45:259-265.
17 Tucci M, Quatraro C, Lombardi L, Pellegrino C, Dammacco F, Silvestris F: Glomerular accumulation of plasmacytoid dendritic cells in active lupus nephritis: role of interleukin-18. Arthritis Rheum 2008;58:251262.

18 Segerer S, Heller F, Lindenmeyer MT, Schmid $\mathrm{H}$, Cohen CD, Draganovici D, Mandelbaum J, Nelson PJ, Grone HJ, Grone EF, Figel AM, Nossner E, Schlondorff D: Compartment specific expression of dendritic cell markers in human glomerulonephritis. Kidney Int 2008;74:37-46.

19 Steinmetz OM, Velden J, Kneissler U, Marx M, Klein A, Helmchen U, Stahl RA, Panzer U: Analysis and classification of B-cell infiltrates in lupus and ANCA-associated nephritis. Kidney Int 2008;74:448-457.

20 Segerer S, Schlondorff D: B cells and tertiary lymphoid organs in renal inflammation. Kidney Int 2008;73:533-537.

21 Veelken R, Vogel EM, Hilgers K, Amann K, Hartner A, Sass G, Neuhuber W, Tiegs G: Autonomic renal denervation ameliorates experimental glomerulonephritis. J Am Soc Nephrol 2008;19:1371-1378.

-22 Scholz J, Lukacs-Kornek V, Engel DR, Specht S, Kiss E, Eitner F, Floege J, Groene HJ, Kurts C: Renal dendritic cells stimulate IL-10 production and attenuate nephrotoxic nephritis. J Am Soc Nephrol 2008; 19:527-537.

23 Fujinaka H, Nameta M, Kovalenko P, Matsuki A, Kato N, Nishimoto G, Yoshida Y, Yaoita E, Naito M, Kihara I, Tomizawa S, Yamamoto T: Periglomerular accumulation of dendritic cells in rat crescentic glomerulonephritis. J Nephrol 2007;20:357-363.

24 Bennett CL, Clausen BE: DC ablation in mice: promises, pitfalls, and challenges. Trends Immunol 2007;28:519-525.

-25 Sapoznikov A, Jung S: Probing in vivo dendritic cell functions by conditional cell ablation. Immunol Cell Biol 2008;86:409-415. 
26 Dong X, Bachman LA, Miller MN, Nath KA, Griffin MD: Dendritic cells facilitate accumulation of IL-17 T cells in the kidney following acute renal obstruction. Kidney Int 2008;74:1294-1309.

-27 Ivanov II, Zhou L, Littman DR: Transcriptional regulation of Th17 cell differentiation. Semin Immunol 2007;19:409-417.

>28 Wu H, Chen G, Wyburn KR, Yin J, Bertolino P, Eris JM, Alexander SI, Sharland AF, Chadban SJ: TLR4 activation mediates kidney ischemia/reperfusion injury. J Clin Invest 2007;117:2847-2859.

29 Nolte MA, Leibundgut-Landmann S, Joffre $\mathrm{O}$, Reis e Sousa C: Dendritic cell quiescence during systemic inflammation driven by LPS stimulation of radioresistant cells in vivo. J Exp Med 2007;204:1487-1501.
0 Rama I, Bruene B, Torras J, Koehl R, Cruzado JM, Bestard O, Franquesa M, Lloberas N, Weigert A, Herrero-Fresneda I, Gulias O, Grinyo JM: Hypoxia stimulus: an adaptive immune response during dendritic cell maturation. Kidney Int 2008;73:816-825.

31 Jantsch J, Chakravortty D, Turza N, Prechtel AT, Buchholz B, Gerlach RG, Volke M, Glasner J, Warnecke C, Wiesener MS, Eckardt KU, Steinkasserer A, Hensel M, Willam C: Hypoxia and hypoxia-inducible factor-1 alpha modulate lipopolysaccharide-induced dendritic cell activation and function. J Immunol 2008;180:4697-4705.

32 Kotsch K, Martins PN, Klemz R, Janssen U, Gerstmayer B, Dernier A, Reutzel-Selke A, Kuckelkorn U, Tullius SG, Volk HD: Heme oxygenase-1 ameliorates ischemia/reperfusion injury by targeting dendritic cell maturation and migration. Antioxid Redox Signal 2007;9:2049-2063.
33 George JF, Braun A, Brusko TM, Joseph R, Bolisetty S, Wasserfall CH, Atkinson MA, Agarwal A, Kapturczak MH: Suppression by CD4+CD25+ regulatory T cells is dependent on expression of heme oxygenase- 1 in antigen-presenting cells. Am J Pathol 2008;173: 154-160.

34 El-Achkar TM, Wu XR, Rauchman M, McCracken R, Kiefer S, Dagher PC: TammHorsfall protein protects the kidney from ischemic injury by decreasing inflammation and altering TLR4 expression. Am J Physiol Renal Physiol 2008;295:F534-F544.

35 Novak N, Bieber T: 2. Dendritic cells as regulators of immunity and tolerance. J Allergy Clin Immunol 2008;121:S370-S374. 